\title{
Exclusive Breastfeeding Practice and Its Association with Breastfeeding Self-Efficacy among Mothers Giving Birth during the COVID-19 Pandemic in Indonesia: A Brief Report
}

\author{
Angelina'), Alicya Lesmanadjaja²), Fransisca Handy Agung1), \\ Gilbert Sterling Octavius ${ }^{2)}$ \\ 1)Child Health Department, Faculty of Medicine, Universitas Pelita Harapan \\ 2)Faculty of Medicine, Universitas Pelita Harapan
}

\section{ABSTRACT}

Background: Breast milk is the best nutrition for most infants, and current recommendations encourage mothers to keep giving breast milk during the COVID-19 pandemic.

Subjects and Method: This is an analytic cross-sectional study involving mothers giving birth since March 2020 and their infants aged under 6 months. An online-based questionnaire, including the Breastfeeding Self-Efficacy Scale-Short Form (BSES-SF), was distributed through social media from April to September 2020. The dependent variable was exclusive breastfeeding rate, and the independent variables were BSES-SF score, mother working status, educational level, place of birth, birth method, and COVID-19 status.

Results: There were 113 respondents, and the rate of exclusive breastfeeding was $79.6 \%$. Self- efficacy score in mothers who give exslusive breastfeeding (Mean $=58.4 ; \mathrm{SD}=0.8$ ) was higher than non exclusive breastfeeding (Mean= 44.8; $\mathrm{SD}=13.4)$ and it was statisfically significant $(\mathrm{p}<0.001)$.

Conclusion: This study showed that during the COVID-19 pandemic exclusive breastfeeding rate might remain high in populartions with good breastfeeding self-efficacy.

Keywords: exclusive breastfeeding, breastfeeding self-efficacy, child nutrition, COVID-19

\section{Correspondence:}

Angelina. Child Health Department, Faculty of Medicine, Universitas Pelita Harapan. Jendral Sudirman 20, Tangerang, Banten, Indonesia. Email: Angelina.fk@uph.edu.

\section{Cite this as:}

Angelina, Lesmanadjaja A, Agung FH, Octavius GS (2021). Exclusive Breastfeeding Practice and Its Association with Breastfeeding Self-Efficacy among Mothers Giving Birth during the COVID-19 Pandemic in Indonesia: A Brief Report. J Matern Child Health. 06(04): 436-443. https://doi.org/10.26911/thejmch.2021.06.04.05.

\section{BACKGROUND}

Current recommendations prioritize breastfeeding for mothers giving birth during a pandemic, including mothers suspected or positively confirmed coronavirus disease 2019 (COVID-19). There is currently no strong evidence that severe acute respiratory syndrome coronavirus-2 (SARS-CoV2), the virus that causes COVID-19, is transmitted through breast milk (CDC and WHO, 2020). Breast milk also contains various antibodies and bioactive com- pounds that play an important role in the immune system so that it will protect against various infections, including respiratory infections (Williams et al., 2020).

However, the data reported a decrease in breastfeeding rates by $40-50 \%$ in some hospitals following the declining rate of early initiation breastfeeding and roomingin practice during COVID-19 pandemic (Bhatt, 2020). One of the factors positively associated with breastfeeding duration and exclusivity is maternal breastfeeding self- 
efficacy, which is reflective of a mother's belief in her ability to succeed in breastfeeding. (Brockway et al., 2007; Otsuka et al., 2014). It is necessary to evaluate breastfeeding self-efficacy because it can be modified to improve the exclusive breastfeeding rate (Dennis, 2003).

There is still not much data regarding the effect of COVID-19 pandemic on the exclusive breastfeeding practice. We aim to evaluate the exclusive breastfeeding rate and maternal breastfeeding self-efficacy in Indonesian women giving birth during the COVID-19 pandemic.

\section{SUBJECTS AND METHOD}

\section{Study Design}

It was a cross-sectional study conducted from April to September 2020. We relied on social media to distribute an announcement containing our study's details.

\section{Population and Sample}

The eligible participants were Indonesian mothers giving birth since March 2020 and their infants aged under 6 months. Mothers with twins or having infants with certain medical problems that were required to fast at early days of birth were excluded. Data collection was done by purposive and snowball sampling using an online-based questionnaire, distributed through social media. The questionnaire consisted of socio-demographic data, questions about breastfeeding practices, and the Breastfeeding Self-efficacy scale-short form (BSES-SF) Indonesian version. There were 14 multiple choice questions to assess infant nutrition given during the COVID-19 pandemic, and some related factors such as early initiation breastfeeding, rooming-in after birth, COVID-19 status infection of mother, and information obtained about breastfeeding practice during the pandemic.

\section{Study Variables}

The Exclusive breastfeeding rate was defined as the proportion of infants who received only breast milk and no other liquid (including formula milk, water, or juice) or solid except for vitamin, mineral supplements, or medicines. Breastfeeding could be delivered either directly or fed expressed.

\section{Operational Definition of Variables} Working status was a mothers' working status; mothers who worked outside the home for income were classified as yes.

Education level was a formal education reached by participants. Elementary and junior high school were classified as primary education. High school was classified as intermediate education. University was classified as high education.

Place of birth was the place where mothers gave birth. Mother and child hospital was a specialty hospital that provided maternal and pediatric services. Private general hospital was a hospital that provided all medical services in general and was managed by a private institution.

Government general public hospital was a hospital that provided all medical services in general and was managed by a government. Other places of birth such as clinics, public health centers, houses, etc were classified as others.

Birth method was the way of childbirth delivery. It was classified as vaginal birth and caesarian section.

COVID-19 status was classified as suspected or confirmed and negative. Mothers with suspected or confirmed COVID-19 were mothers who resulted in a reactive antibody of SARS-CoV-2 in a blood sample or positive SARS CoV-2 antigen/RNA in nasopharyngeal swab sample.

Breastfeeding self-efficacy was defined as mother's belief in her ability to succeed 
in breastfeeding. It was measured by the BSES-SF.

\section{Study Instruments}

The BSES-SF instrument has 14 items with a 5-point Likert-type scale, with responses from not at all confident (1) to always confident (5). Total scores can range from 14 to 70 , higher scores reflect better breastfeeding self-efficacy (Tuthill, 2016). The BSES-SF has been translated and validated to the Indonesian version from previous studies (Handayani, 2013; Wardani, 2012).

\section{Data Analysis}

The data were analyzed with IBM SPSS Statistics version 24.0 and expressed as numbers and percentages. The Chi-square, Fischer's exact test, and independent t-test were used for bivariate analysis. Odds ratios (OR) and 95\% confidence interval (CIs) were also calculated, differences with $\mathrm{p}<0.005$ were considered significant.

\section{Research Ethics}

This study was approved by the Ethics Committee of Faculty of Medicine, Pelita Harapan University, No. 149/K-LKJ/ETIK/VII/2020.

\section{RESULTS}

\section{Sample Characteristics}

Table 1 reported the results od respondent characteristics. Table 1 showed that there were 113 respondents, most of them were under 40 years old (98.3\%) and highly educated (90.3\%).

Table 1. Respondent Characteristics

\begin{tabular}{|c|c|c|c|}
\hline Variables & Category & Frequency (N) & Percentage (\%) \\
\hline \multicolumn{4}{|l|}{ Mothers } \\
\hline \multirow[t]{3}{*}{ Age (year) } & $20-29$ & 55 & 48.7 \\
\hline & $30-39$ & 56 & 49.6 \\
\hline & $40-49$ & 2 & 1.8 \\
\hline \multirow[t]{2}{*}{ Education level } & Middle low & 11 & 90.3 \\
\hline & High & 102 & 66.4 \\
\hline \multirow[t]{2}{*}{ Working status } & Yes & 75 & 66.4 \\
\hline & No & 38 & 33.6 \\
\hline Antenatal & Obstetrician & 99 & 87.6 \\
\hline \multirow[t]{2}{*}{$(\mathrm{ANC})$} & Midwife & 13 & 11.5 \\
\hline & Never & 1 & 0.9 \\
\hline \multirow[t]{4}{*}{ Place of Birth } & Mother and child hospital & 31 & 27.4 \\
\hline & Private general hospital & 49 & 43.4 \\
\hline & Government general hospital & 18 & 15.9 \\
\hline & Others & 15 & 13.3 \\
\hline \multirow[t]{2}{*}{ Birth method } & Vaginal birth & 48 & 42.5 \\
\hline & Cesarean section & 65 & 57.5 \\
\hline \multicolumn{4}{|l|}{ Infants } \\
\hline \multirow[t]{4}{*}{ Gestational age } & Pre-term & 18 & $15 \cdot 9$ \\
\hline & Aterm & 92 & 81.4 \\
\hline & Post-term & 1 & 0.9 \\
\hline & Not sure & 2 & 1.8 \\
\hline \multirow[t]{3}{*}{ Birth weight (gram) } & $<2500$ & 2 & 1.8 \\
\hline & $2500-4000$ & 109 & 96.4 \\
\hline & $>4000$ & 2 & 1.8 \\
\hline \multirow[t]{3}{*}{ Chronological age } & $<1$ month & 17 & 15.0 \\
\hline & 1-3 month & 76 & $67 \cdot 3$ \\
\hline & 3-6 month & 20 & 17.7 \\
\hline \multirow[t]{2}{*}{ Perinatology ward } & Yes & 14 & 12.4 \\
\hline & No & 99 & 87.6 \\
\hline
\end{tabular}


Table 1 showed that antenatal examinations were generally carried out by obstetricians, and more than $50 \%$ of respondents gave birth by cesarean section. Almost all infants were born at term with normal birth weight and did not require treatment in perinatology wards, when filling out the questionnaire, more than $60 \%$ of infants were aged 1-3 months old.

Table 2 reported factors associated with breastfeeding practices. Table 2 showed that a total of 49 respondents (43.4\%) underwent testing related to COVID-19 infection, 3 were confirmed with COVID-19 by positive results for SARSCoV-2 RNA in nasopharyngeal swab, 3 were suspected based on the reactive antibody of SARS-CoV-2 using rapid detection kits (RDT) and imaging findings. As much as $30 \%$ of respondents received information about breastfeeding practices during the COVID-19 pandemic, mostly from health care professionals and social media. Twelve infants received merely formula milk while still in health facilities, 21 (72.4\%) were suggested by health care professionals with the most common reasons were dehydration, inadequate breast milk supply, and hyperbilirubinemia. The exclusive breastfeeding rate in this study was $79.6 \%$.

Table 2. Breastfeeding practices and its related factors

\begin{tabular}{|c|c|c|c|}
\hline Characteristics & Category & $\mathbf{N}$ & $\%$ \\
\hline \multirow{5}{*}{$\begin{array}{l}\text { Information about } \\
\text { breastfeeding practices } \\
\text { during the pandemic }\end{array}$} & None & 75 & 66.4 \\
\hline & Yes & 38 & 33.6 \\
\hline & - Healthcare professional & 14 & \\
\hline & - $\quad$ Social media & 9 & \\
\hline & $\begin{array}{l}\text { - Many sources (healthcare } \\
\text { professional/social } \\
\text { media/friends/relatives) }\end{array}$ & 15 & \\
\hline \multirow{2}{*}{$\begin{array}{l}\text { Early initiation of } \\
\text { breastfeeding }\end{array}$} & Yes & 69 & 61.1 \\
\hline & No & 44 & 38.9 \\
\hline \multirow[t]{2}{*}{ Rooming-in practice } & Yes & 91 & 80.5 \\
\hline & No & 22 & 19.5 \\
\hline \multirow{4}{*}{$\begin{array}{l}\text { Nutrition } \\
\text { facilities }\end{array}$} & Direct breastfeeding & 74 & 65.5 \\
\hline & Expressed breastmilk & 1 & 0.9 \\
\hline & Formula milk & 12 & 10.6 \\
\hline & $\begin{array}{l}\text { Mixed (direct/expressed/donor breastmilk/ } \\
\text { formula milk) }\end{array}$ & 26 & 23 \\
\hline \multirow[t]{4}{*}{ Nutrition at home } & Direct breastfeeding & 56 & 49.5 \\
\hline & Expressed breast milk & 3 & 2.7 \\
\hline & Formula milk & 3 & 2.7 \\
\hline & Mixed (direct/expressed/donor & 51 & 45.1 \\
\hline \multirow[t]{2}{*}{ Exclusive breastfeeding } & Yes & 90 & 79.6 \\
\hline & No & 23 & 20.4 \\
\hline
\end{tabular}

\section{Bivariate Analysis}

Table 3 showed the results of bivariate analysis using Chi-square or Fisher's exact test. There was a significant difference in mean BSES-SF score between respondents who provided exclusive breastfeeding and respondents who did not exclusively breastfeed $(95 \% \mathrm{CI}=7.86$ to $19.35 ; \mathrm{p}<0.001)$. 
Angelina et al./ Exclusive Breastfeeding and Breastfeeding Efficacy during the COVID-19 Pandemic

There was no significant association between exclusive breastfeeding practice and mother working status (95\% CI 0.23 to $1.4 ; \mathrm{p}=0.214$ ), education level for intermediate education ( $95 \% \mathrm{CI}=0.09$ to 44.35 ; $\mathrm{p}=1.000$ ) and for high education (95\% CI= 0.23 to $64.26 ; p=0.380$ ), place of birth for private general hospital $(95 \% \mathrm{CI}=0.25$ to 2.23; $\mathrm{p}=0.592$ ), for government general hospital $\mathrm{p}=496$; $95 \%$ CI 0.16 to 2.44 , for others (95\% CI= 0.11 to $3.63 ; \mathrm{p}=1.000$ ), birth method (95\% CI= 0.28 to $1.77 ; \mathrm{p}=$ 0.458), and maternal COVID-19 status (95\% $\mathrm{CI}=0.05$ to $1.37 ; \mathrm{p}=0.121$ ).

Table 3. Association of BSES-SF score and exclusive breastfeeding practice

\begin{tabular}{lcccccc}
\hline \multirow{2}{*}{ Group } & \multicolumn{2}{c}{ BSES-SF Score } & & \multicolumn{2}{c}{ 95\% CI } & \multirow{2}{*}{ p } \\
\cline { 2 - 3 } \cline { 5 - 6 } & Mean & SD & & Lower limit & Upper limit & \\
\hline Exclusive breastfeeding & 58.4 & 0.8 & & 7.86 & 19.35 & $<0.001$ \\
Non-exclusive breastfeeding & 44.8 & 13.4 & & & \\
\hline
\end{tabular}

Table 4. Association of exclusive breastfeeding with some related factors

\begin{tabular}{|c|c|c|c|c|c|c|}
\hline \multirow[t]{2}{*}{ Variables } & \multicolumn{2}{|c|}{ Exclusive breastfeeding } & \multirow[t]{2}{*}{ OR } & \multicolumn{2}{|l|}{ 95\%CI } & \multirow[t]{2}{*}{$\mathrm{P}$} \\
\hline & Yes (\%) & No (\%) & & $\begin{array}{l}\text { Lower } \\
\text { limit }\end{array}$ & $\begin{array}{l}\text { Upper } \\
\text { limit }\end{array}$ & \\
\hline \multicolumn{7}{|l|}{ Working status } \\
\hline Yes & $61(69.3)$ & $14(56)$ & 0.56 & 0.23 & 1.4 & 0.214 \\
\hline No & $27(30.7)$ & $11(44)$ & & & & \\
\hline \multicolumn{7}{|l|}{ Education level } \\
\hline Primary & $1(1.1)$ & $1(4)$ & Reff & & & \\
\hline Intermediate & $6(6.8)$ & $3(12)$ & 2.00 & 0.09 & 44.35 & 1.000 \\
\hline High & $81(92.1)$ & $21(84)$ & 3.86 & 0.23 & 64.26 & 0.380 \\
\hline \multicolumn{7}{|l|}{ Place of Birth } \\
\hline Mother and child hospital & $25(28.4)$ & $6(24)$ & Reff & & & \\
\hline Private general hospital & $37(42)$ & $12(48)$ & 0.74 & 0.25 & 2.23 & 0.592 \\
\hline $\begin{array}{l}\text { Government general } \\
\text { hospital }\end{array}$ & $13(14.8)$ & $4(20)$ & 0.62 & 0.16 & 2.44 & 0.496 \\
\hline Others & $13(14.8)$ & $2(8)$ & 0.64 & 0.11 & 3.63 & 1.000 \\
\hline $\begin{array}{l}\text { Birth method } \\
\text { Vaginal birth } \\
\text { Cesarean section }\end{array}$ & $\begin{array}{l}39(44.3) \\
49(55 \cdot 7)\end{array}$ & $\begin{array}{l}9(36) \\
16(64)\end{array}$ & 0.71 & 0.28 & 1.77 & 0.458 \\
\hline $\begin{array}{l}\text { COVID-19 status } \\
\text { Suspected/confirmed } \\
\text { Negative }\end{array}$ & $\begin{array}{l}3(3.4) \\
85(96.6)\end{array}$ & $\begin{array}{l}3(12) \\
22(88)\end{array}$ & 0.26 & 0.05 & 1.37 & 0.121 \\
\hline
\end{tabular}

\section{DISCUSSION}

This was the first study that assess breastfeeding practice in Indonesia during the COVID-19 pandemic. The rate of exclusive breastfeeding in our study was $79.6 \%$. It was higher than the data from national census and other studies which showed the exclusive breastfeeding rate in Indonesia ranged from $40-50 \%$ (Central Bureau of
Statistics, 2018; Ananta et al., 2016; Yohmi et al., 2015).

This result was quite surprising because it was assumed that the breastfeeding rate would have declined during the pandemic. Some possibilities may explain this result. First, a large proportion of study respondents had good breastfeeding self- 
efficacy, based on the mean score of BSES$\mathrm{SF}$ questionnaire (Mean= 55.4; $\mathrm{SD}=1.02)$. There is no universal cut-off point used to classify BSES-SF score. A study by Nankumbi et al. (2019) in Uganda considered a score of more than 50 as high breastfeeding self-efficacy. Another Study by Nanishi et al (2015) was conducted to determine a cut-off point for scores of BSES-SF in Japan, and the result showed that a BSES-SF score above 50 was a good predictor of continuity of exclusive breastfeeding after discharged.

Second, there was only $5.3 \%$ of respondents suspected or confirmed with COVID-19 infection. Most of the respondents (92\%) in this study were healthy and asymptomatic, and only $43.4 \%$ of respondents were investigated for COVID-19 infection. Screening of COVID-19 infection in pregnant women was not routinely done at this study period, and some healthcare facilities in Indonesia still generally use antibody-based rapid detection kits (RDT) to detect COVID-19 infection in hospitalized patients. It might obscure the pandemic effect on the exclusive breastfeeding rate in the study.

There was a significant difference in the mean score of BSES-SF between groups with exclusive breastfeeding and not exclusively breastfed ( $p<0.001)$. It showed that improving the BSES-SF score could indeed increase the exclusive breastfeeding rate. The BSES-SF questionnaire consists of statements describing breastfeeding techniques, mothers' attitude and beliefs related to successful breastfeeding experience. It was adapted from Bandura's social cognitive theory, which postulated that breastfeeding self-efficacy was influenced through previous breastfeeding experiences, observed successful breastfeeding behaviors by others, encouragement from significant others to breastfeed, and current physical and affective state (Dennis 2003). Educational interventions (providing information, demonstrations, and discussions) and supportive interventions (social support, counseling, consultation) were effective to improve the BSES-SF score.

A meta-analysis by Brockway et al. (2017) showed that interventions were most successful when focused on education, delivered in both hospital and community settings, implemented in the postpartum period, and using multiple contact points. Another study in postpartum Chinese mothers found that mothers' breastfeeding self-efficacy was highly related to their perceived social supports from husband and nurses/midwives. Nurses and midwives have a vital role in promoting breastfeeding self-efficacy during the hospital stay, especially for new mothers (Yang et al., 2016).

Dissemination of information regarding breastfeeding practices during the pandemic is still lacking, 30\% of respondents received that information, and only $20 \%$ of respondents received information directly from health professionals. Social media plays an important role in information dissemination at this time, but unfortunately, some studies showed lots of inaccurate information about COVID-19 came from social media, causing panic and excessive worries (Ahmad 2020; Islam 2020). Health professionals are expected to be more active in providing accurate information and play a supportive role for breastfeeding mothers during the pandemic. The use of technology for virtual meetings or teleconsultation can probably be an option during this pandemic. The limitation of this study was the use of an online-based questionnaire, thus limited the study respondents only to mothers who familiar and fluent in using internet technology. Data from the World Bank in 2019 showed that not more than 
$50 \%$ of the population in Indonesia using the internet, so respondents in this study might not represent the overall maternal population in Indonesia.

This study concluded that exclusive breastfeeding rate in Indonesian mothers giving birth during the COVID-19 pandemic was high, and their breastfeeding self-efficacy was good. There was a significant difference in mean BSES-SF scores between groups with exclusive breastfeeding and not exclusively breastfed. It showed that during the COVID-19 pandemic exclusive breastfeeding rate might remain high in populations with good breastfeeding self-efficacy. A follow-up study with larger population coverage is needed to more represent the Indonesian maternal population.

\section{FUNDING AND SPONSORSHIP}

None

\section{CONFLICT OF INTEREST}

None declared

\section{ACKNOWLEDGEMENT}

The authors would like to thank all of the participants in this study.

\section{REFERENCE}

Ahmad AR, Murad HR (2020). The impact of social media on panic during the COVID-19 pandemic in Iraqic Kurdistan: online questionnaire study. J Med Internet Res. 22: 1-11. doi: 10.2196/19556.

Ananta Y, Gandaputra E, Waiman E, Partiwi IGAN, Marzuki NS, Yohmi $\mathrm{E}$, et al. (2016). Exclusive breastfeeding rate and factors associated with infant feeding practices in Indonesia. Paediatr Indones. 56: 2431. doi: 10.14238/pi56.1.2016.24-31.
Bhatt N (2020). Breastfeeding in India is disrupted as mothers and babies are separated in the pandemic. BMJ, 370: 1-3. doi: 10.1136/bmj.m3316.

Brockway M, Benzies K, Hayden KA (2017). Interventions to improve breastfeeding self-efficacy and resultant breastfeeding rates: a systematic review and meta-analysis. J Hum Lact, 33: 486-99. doi: 10.1177/o890334417707957.

Centers for Disease Control and Prevention (2020). Care for Breastfeeding Women. Available at: https://www.cdc.gov/coronavirus/2019-ncov/hcp/care-for-breastfeeding-women.html. (Accessed December 2020).

Central Bureau of Statistics (2018). Percentage of infants aged less than 6 months who gained exclusive breastfeeding by province. Online . Available from: https://www.bps.go.id/dynamictable/2018/06/05/14 30/persentase-bayi-usia-kurangdari-6-bulan-yang-mendapatkanasi-eksklusif-menurut-provinsi2015-2016.html. (Accessed September 1, 2020).

Dennis C (2003). The breastfeeding selfefficacy scale: psychometric assessment of the short form. JOGNN, 32: 734-44. doi: 10.1177/0884217503258459 .

Handayani L, Kosnin A, Jiar YK, Solikhah (2013). Translation and validation of breastfeeding self-efficacy scaleshort form (BSES-SF) into Indonesian: a pilot study. KES MAS. 7: 216. doi: 10.12928/kesmas.v7i1.1023.

Islam S, Sarkar T, Khan SH, Kamal AHM, Hasan SMM, Kabir A, et al. (2020). COVID-19-Related infodemic and its impact on public health: a global 
social media analysis. Am J Trop Med Hyg, oo: 1-9. doi: https://doi.org/10.4269/ajtmh.20-0812.

Nanishi K, Green J, Taguri M, Jimba M. (2015). Determining a cut-off point for scores of the breastfeeding selfefficacy scale-short form: secondary data analysis of an intervention study in Japan. PloS One, 10: 1-12. https://www.ncbi.nlm.nih.gov/pmc /articles/PMC4480881/\#.

Nankumbi J, Mukama AA, Ngabirano TD (2019). Predictors of breastfeeding self-efficacy among women attending an urban postnatal clinic, Uganda. Nursing Open, 6: 765-71. doi: 10.1002/nop2.257.

Otsuka K, Taguri M, Dennis C, Wakutani $\mathrm{K}$, Awano M, Yamaguchi T, et al. (2014). Effectiveness of a breastfeeding self-efficacy intervention: do hospital practices make a different? Matern Child Health, 18: 296-306. doi: 10.1007/s10995-013-1265-2.

Tuthill EL, McGrath JM, Graber M, Cusson RM, Young SL (2016). Breastfeeding self-efficacy: a critical review of available instruments. $\mathrm{J}$ Hum Lact, 32: 35-45. doi: 10.1177/0890334415599533.

The World Bank (2019). Individuals using the internet (\% population) - Indonesia. Online. Available from: https://data.worldbank.org/indicator/IT. NET.USER.ZS?locations=ID. (Accessed September 2, 2020).

Wardani MA (2012). Breastfeeding selfefficacy in primigravide mothers.
Thesis. University of Indonesia. Available from: http://lib.ui.ac.id/file?file=digital\%2F20311620-S43369-Gambaran+tingkat.pdf. (Accessed March 2, 2020).

Williams J, Namazova-Baranova L, Weber M, Vural M, Mestrovic J, Carrasco-Sanz A, et al. (20202). The importance of continuing breastfeeding during Coronavirus Disease2019: in support of the World Health Organization Statement on breastfeeding during the pandemic. J Pediatr, 223: 234-6. doi: 10.1016/j.jpeds.2020.05.009.

World Health Organization (2020). Breastfeeding and COVID-19. Available from: https://www.who.int/news-room/commentaries/detail/breastfeeding-and-covid-19. (Accessed September 1, 2020).

Yang X, Gao LL, Ip WY, Chan WCS (2016). Predictors of breast feeding self-efficacy in the immediate postpartum period: a cross-sectional study. Midwifery, 41: 1-8. doi: 10.1016/j.midw.2016.07.011.

Yohmi E, Marzuki NS, Nainggolan E, Partiwi IGAN, Syarif BH, Oswari H (2015). Prevalence of exclusive breastfeeding in Indonesia: a qualitative and quantitative study. Paediatr Indos, 55(6): 302-8. https://doi.org/10.14238/pi55.6.2015.302-

8. 